\title{
A biogeochemical model of Lake Pusiano (North Italy) and its use in the predictability of phytoplankton blooms: first preliminary results
}

\author{
Diego COPETTI*, Gianni TARTARI, Giuseppe MORABITO ${ }^{1)}$, Alessandro OGGIONI ${ }^{1)}$, Elena LEGNANI and \\ Jörg IMBERGER ${ }^{2)}$
}

CNR - Water Research Institute, 20047 Località Occhiate, Brugherio, Italy

${ }^{1)}$ CNR- Institute of Ecosystem Study, Largo Tonolli 50, 28922 Verbania Pallanza, Italy

${ }^{2)}$ Centre for Water Research, The University of Western Australia, Nedlands, 6907, WA, Australia

*e-mail corresponding author: copetti@irsa.cnr.it

\begin{abstract}
This study reports the first preliminary results of the DYRESM-CAEDYM model application to a mid size sub-alpine lake (Lake Pusiano North Italy). The in-lake modelling is a part of a more general project called Pusiano Integrated Lake/Catchment project (PILE) whose final goal is to understand the hydrological and trophic relationship between lake and catchment, supporting the restoration plan of the lake through field data analysis and numerical models. DYRESM is a 1D-3D hydrodynamics model for predicting the vertical profile of temperature, salinity and density. CAEDYM is multi-component ecological model, used here as a phytoplankton-zooplankton processes based model, which includes algorithms to simulate the nutrient cycles within the water column as well as the air-water gas exchanges and the water-sediments fluxes. The first results of the hydrodynamics simulations underline the capability of the model to accurately simulate the surface temperature seasonal trend and the thermal gradient whereas, during summer stratification, the model underestimates the bottom temperature of around $2{ }^{\circ} \mathrm{C}$. The ecological model describes the epilimnetic reactive phosphorus $\left(\mathrm{PO}_{4}\right)$ depletion (due to the phytoplankton uptake) and the increase in $\mathrm{PO}_{4}$ concentrations in the deepest layers of the lake (due to the mineralization processes and the sediments release). In terms of phytoplankton dynamics the model accounts for the Planktothrix rubescens dominance during the whole season, whereas it seems to underestimate the peak in primary production related to both the simulated algal groups (P. rubescens and the rest of the other species aggregated in a single class). The future aims of the project are to complete the model parameterization and to connect the in-lake and the catchment modelling in order to gain an integrated view of the lake-catchment ecosystem as well as to develop a three dimensional model of the lake.
\end{abstract}

Key words: biogeochemical models, Planktothrix rubescens, Lake Pusiano

\section{INTRODUCTION}

Many studies underline the significance of coupled hydrodynamics-ecological models in both limnological processes understanding and management of lacustrine environments (Hamilton \& Schladow 1997; Omlin et al. 2001) as they allow simulating chemical and biological dynamics in a proper physical contest rather than under simplified conditions (such as continuously mixed condition or two box approximation).

The adaptation of a biogeochemical model for Lake Pusiano is a part of the Pusiano Integrated Lake/ catchment Project (PILE) which aims at understanding the hydrological and trophic relationships between lake and catchment through field data analysis and numerical models. The applied goal of the project is to support the restoration and the management plans of the lake ecosystem.

This preliminary study aims at presenting the state of the art of the biogeochemical model's development and at discussing the first model simulations of the 2002 limnological year.

\section{STUDY SITE}

Lake Pusiano is a mid-size (surface area $5 \mathrm{~km}^{2}$ ) warm monomictic sub-alpine lake, with a maximum depth of around $24 \mathrm{~m}$ and a residence time less than one year. In terms of trophic conditions the ecosystem is characterized by phosphorus limitation (Legnani et al. 2005). The limnological features of this environment have considerably changed during the last 30 years. In particular the trend of total phosphorus (TP) concentrations indicates a sharp decrease of this nutrient in the last 15 years (1984 winter overturn $=198 \mu \mathrm{g} \mathrm{P} \mathrm{l}^{-1}, 2004$ winter overturn $\left.=67 \mu \mathrm{g} \mathrm{P}^{-1}\right)$. Despite this reduction of the TP concentrations since 1994 Lake Pusiano has suffered conspicuous cyanobacterial blooms. During 2002 the lake was strongly dominated by the filamentous cyanobacterium Planktothrix rubescens, whereas the following year the phytoplankton population shifted toward a more diversified condition with crysophytes and chlorophytes as dominant groups (Legnani et al. 2005). 


\section{METHODS}

In this study the physical and chemical-biological processes occurring on the Lake Pusiano at the seasonal scale have been simulated by coupling the hydrodynamics model DYRESM with the ecological model CAEDYM.

DYRESM (DYnamic REservoir Simulation Model) is a 1D - 3D hydrodynamics model for predicting the vertical distribution of temperature, salinity and density in lakes and reservoirs at the seasonal or decadal time scales (Antenucci \& Imerito 2002). The model assumes that the horizontal density gradients quickly equilibrate horizontal parameter variations and that it is sufficient to keep track of only the vertical structure (1D approximation) and the lake may be represented by a series of horizontal layers of uniform property but variable thickness. These layers or slabs are assumed to be Lagrangian in nature and move vertically in response to inflows and outflows entering the lake structure either above or below a particular slab. The model accounts for surface hydrodynamics (balance of heat and momentum), inflow and outflow dynamics and internal mixing processes driven by external forcing mechanisms; in this sense it accounts for 3D processes, but retains only the memory of what these processes do to the vertical structure. The model uses as input forcing hourly or daily meteorological data (incident short wave radiation, long wave radiation, air temperature, wind speed, vapour pressure and rainfall), daily inflow and volumes, salinities and temperatures and outflow volumes. When the hydrodynamics model is coupled with CAEDYM the daily inflow concentrations of the water quality variables are also required.

CAEDYM (Computational Aquatic Ecosystem DYnamics Model) is a multivariable generalized ecological model, but in this application, only a subset of the algorithms was activated. These included algorithms to simulate the population dynamics of the main freshwater phytoplankton and zooplankton groups. Primary production and the influence of light availability, nutrients, temperature as well as grazing on phytoplankton constituted the basis for the phytoplankton-zooplankton model. The algorithms to dynamically simulate the airwater gas exchanges and the water-sediment fluxes (Romero et al. 2003) were also activated.

The current version of the Lake Pusiano ecological model was structured in order to simulate, with a daily time step, the following biogeochemical cycles: nitrogen and phosphorus dynamics, the dynamics of 2 phytoplankton groups ( $P$. rubescens and the rest of the phytoplankton species aggregated in a single class G2) and of 1 zooplankton group (herbivores). For a complete description of the Lake Pusiano model readers are referred to Copetti (2005) and to Romero et al. (2003) for the CAEDYM code. The following model description focuses only on the phosphorus-phytoplankton submodel.
The phytoplankton dynamics was computed for each group (at a give time step and dynamic layer) with the following equation:

$$
\frac{d A i}{d t}=\left\{\mu_{\max }\left[\min \left|f_{I}(I), f_{P}(P), f_{N}(N)\right| f_{T}(T)\right]-L-G-S\right\} A i
$$

where Ai ( $\mu \mathrm{g}$ Chl- $\left.a \mathrm{l}^{-1}\right)$ is the chlorophyll concentration of a given phytoplankton group ( $P$. rubescens or $\mathrm{G} 2$ in this study), $\mu_{\max }\left(\mathrm{day}^{-1}\right)$ is the maximum growth rate at $20{ }^{\circ} \mathrm{C}$ in absence of limitation by nutrients and light, $f_{I}(I), f_{P}(P)$ and $f_{N}(N)$ are limiting expressions for light, phosphorus and nitrogen respectively, $f_{T}(T)$ is a function for temperature dependence, $L$ accounts for metabolic losses, $G$ for grazing due to zooplankton and $S$ for biomass losses due to settling.

The algorithm proposed by Wallas et al. (1996) was used to account for photo-inhibition, (Walsby 2001), for P. rubescens:

$$
f_{I}(I)=\frac{I}{I_{S}} \exp \left(1-\frac{I}{I_{S}}\right)
$$

where $I\left(\mu \mathrm{mol} \mathrm{m} \mathrm{m}^{-2} \mathrm{~s}^{-1}\right)$ is the incoming irradiance, $I_{S}$ $\left(\mu \mathrm{mol} \mathrm{m} \mathrm{m}^{-2} \mathrm{~s}^{-1}\right)$ represents the light saturation value at which production is maximal.

For the rest of the phytoplankton species (G2) a simple Webb type model was applied (Webb et al. 1974):

$$
f_{I}(I)=1-\exp \left(\frac{I}{I_{k}}\right)
$$

where $I_{k}\left(\mu \mathrm{mol} \mathrm{m} \mathrm{m}^{-2} \mathrm{~s}^{-1}\right)$ is the light intensity at which the photosynthetic ratio is equivalent to the maximum production.

The incident surface short wave radiation was supplied by the hydrodynamics model and was converted to photosynthetically active radiation (PAR; 400-700 nm) by assuming $45 \%$ of the incident spectrum was active (Jellison \& Melack 1993). The photosynthetic component was assumed to penetrate the water column according to Beer's Law:

$$
I_{z}=I_{0}^{K d z}
$$

where $I_{z}\left(\mu \mathrm{mol} \mathrm{m} \mathrm{m}^{-2} \mathrm{~s}^{-1}\right)$ is the radiance at a certain depth $z, I_{0}\left(\mu \mathrm{mol} \mathrm{m} \mathrm{m}^{-2} \mathrm{~s}^{-1}\right)$ is the surface incoming radiation and $K_{d}\left(\mathrm{~m}^{-1}\right)$ is the light extinction coefficient. In this study the light adsorption was dominated by the attenuation due to pure water and the presence of algae, so that the total $K_{d}$ could be computed with the following equation:

$$
K_{d}=K_{d}^{w}+\sum_{i}^{G i} K_{e}^{A i} A_{i}
$$

were $K_{d}^{w}\left(\mathrm{~m}^{-1}\right)$ is the attenuation coefficient due to pure water $\left(0.33 \mathrm{~m}^{-1}\right), K_{e}\left(\mathrm{~m}^{2} \mathrm{mg} \mathrm{Chl}-a^{-1}\right)$ is the rate at which the extinction coefficient increases with increasing the chlorophyll concentration 


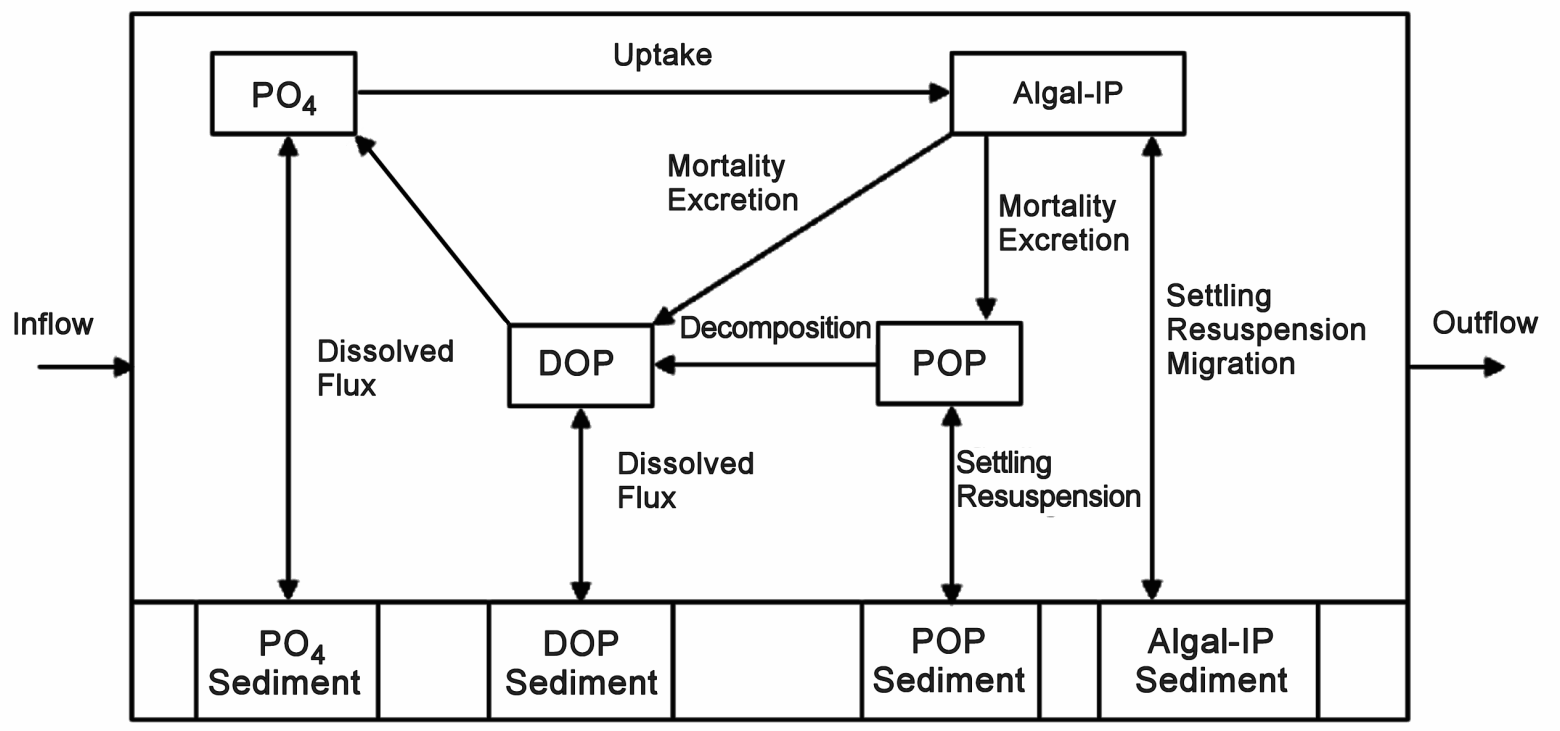

Fig. 1. Simplified schematic of the phosphorus-phytoplankton model. $\mathrm{PO}_{4}=$ dissolved reactive phosphorus, DOP $=\mathrm{Dissolved}$ Organic Phosphorus, POP = Particulate Organic Phosphorus, Algal-IP = Algal Internal Phosphorus.

$\left(A_{i}, \mu \mathrm{g}\right.$ Chl- $\left.a \mathrm{l}^{-1}\right)$ and $G_{i}$ denote a given phytoplankton group.

For both algal groups the phosphorus and nitrogen limitation function was assumed to be controlled by a dynamic internal nutrient process. The phosphorus function takes form as follows:

$$
f(P)=\frac{I P_{\max }}{I P_{\max }-I P_{\min }}\left[1-\frac{I P_{\min }}{I P}\right]
$$

where $I P_{\max }\left(\mathrm{mg} \mathrm{P}\right.$ mg Chl- $\left.a^{-1}\right)$ and $I P_{\min }(\mathrm{mg} \mathrm{P}$ mg Chl$\left.a^{-1}\right)$ are user defined bounds for internal phosphorus concentrations, IP (mg P mg Chl- $a^{-1}$ ) is the actual internal phosphorus content at a given time step. The phosphorus uptake function was modeled with:

$$
U_{P O_{4}}=U P_{\max }\left[f_{T}(T) \frac{I P_{\max }-I P}{I P_{\max }-I P_{\min }} \frac{P O_{4}}{P O_{4}+K_{P}}\right] A_{i}(7
$$

where $U P_{\max }\left(\mathrm{mg} \mathrm{P}\right.$ mg Chl- $\left.a^{-1} \mathrm{day}^{-1}\right)$ is the maximum phosphorus uptake, $\mathrm{PO}_{4}\left(\mathrm{mg} \mathrm{P} \mathrm{l}^{-1}\right)$ is the external dissolved reactive phosphorus concentration and $K_{P}(\mathrm{mg}$ $\left.\mathrm{P}^{-1}\right)$ is the half saturation coefficient. The temperature function $f_{T}(T)$ included limitation at high temperature and was identical to that used for phytoplankton growth (see below).

A similar formulation was applied to nitrogen to ensure the uptake of both the external nitrate and ammonium concentrations were accounted for. As the system is phosphorus limited the description of the phytoplankton-nitrogen dynamics is not reported here.

The temperature function $f_{T}(T)$ accounts for changes in growth rate due to temperature and was assumed to be given by:

$$
f_{T}(T)=\vartheta_{G}{ }^{T-20}-\vartheta_{G}{ }^{K(T-a)}+b
$$

where $T\left({ }^{\circ} \mathrm{C}\right)$ is the water temperature, $\vartheta_{G}$ is a non dimensional temperature multiplier prescribed by the user. By defining $T_{o p t}, T_{\max }$ and $T_{s}$ the temperature at which $f_{T}(T)$ is maximal, zero and equal to 1 respectively, the model solves the equation which accounts for inhibition at higher temperatures [see Romero et al. (2003), for details].

Loss processes $(L)$ were simulated with a lumped term that included the effects of respiration, mortality and excretion:

$$
L=K_{R} \vartheta_{R}^{T-20}
$$

where $K_{R}\left(\right.$ day $\left.^{-1}\right)$ is the "respiration" rate coefficient although it also includes the effects of mortality and excretion, $\vartheta_{R}$ is a non-dimensional multiplier and $\mathrm{T}\left({ }^{\circ} \mathrm{C}\right)$ is the water temperature. In the model a certain percentage (fixed by the user) of these metabolic losses (morality and excretion) goes into the Particulate Organic Matter (POM) pool and the remainder goes to the Dissolved Organic Matter (DOM) pool. Figure 1 shows schematically the fate of different dissolved and particulate phosphorus species as assumed in CAEDYM.

Mortality due to grazing (G) was based on a Michaelis-Menten type equation (not shown). The model allows users to fix the preference of each zooplankton group for a given phytoplankton class (in terms of diet percentage). In this study, since $P$. rubescens is grazed only lightly by zooplankton (Kurmayer \& Jüttner 1999), the herbivores pressure was applied only to the G2 group. 
Tab. 1. Principal parameters of the phosphorus-phytoplankton model.

\begin{tabular}{|c|c|c|c|c|c|c|}
\hline Process & Equation & Symbols & P. rubescens & Chlorophytes & literature range & Unit \\
\hline growth & (1) & $\mu_{\max }$ & 0.12 & 0.9 & $0.12-3.63$ & day $^{-1}$ \\
\hline light limitation & $\begin{array}{l}(2) \\
(3)\end{array}$ & $\begin{array}{l}I_{s} \\
I_{k}\end{array}$ & 20 & 100 & $\begin{array}{l}20-300 \\
20-300\end{array}$ & $\begin{array}{l}\mu \mathrm{mol} \mathrm{m} \mathrm{m}^{-2} \mathrm{~s}^{-1} \\
\mu \mathrm{mol} \mathrm{m} \mathrm{m}^{-2} \mathrm{~s}^{-1}\end{array}$ \\
\hline light estinction & $(5)$ & $K_{e}$ & 0.033 & 0.025 & $0.01-15.1$ & $\mathrm{~m}^{2}(\mathrm{mg} \mathrm{Chl}-a)^{-1}$ \\
\hline $\begin{array}{l}\text { phosphorus } \\
\text { limitation }\end{array}$ & (6) & $\begin{array}{l}I P_{\max } \\
I P_{\min }\end{array}$ & $\begin{array}{l}2.0 \\
0.3\end{array}$ & $\begin{array}{l}2.0 \\
0.3\end{array}$ & $\begin{array}{c}0.95-10.9 \\
0.1-1\end{array}$ & $\begin{array}{l}\text { mg P (mg Chl- } a)^{-1} \\
\text { mg P (mg Chl- } a)^{-1}\end{array}$ \\
\hline $\begin{array}{l}\text { phosphorus } \\
\text { uptake }\end{array}$ & (7) & $\begin{array}{c}U P_{\max } \\
\mathrm{K}_{\mathrm{P}}\end{array}$ & $\begin{array}{l}0.05 \\
0.02\end{array}$ & $\begin{array}{l}0.05 \\
0.02\end{array}$ & $\begin{array}{c}0.14-1 \\
0.001-0.03\end{array}$ & $\begin{array}{c}\operatorname{mg~P}(\operatorname{mg~Chl}-a)^{-1} \text { day }^{-1} \\
\mathrm{mg} \mathrm{P} \mathrm{P}^{-1}\end{array}$ \\
\hline $\begin{array}{l}\text { temperature } \\
\text { dependence }\end{array}$ & (8) & $\begin{array}{c}\mathrm{T}_{\max } \\
\mathrm{T}_{\text {opt }} \\
\mathrm{T}_{\text {sta }} \\
\vartheta_{G}\end{array}$ & $\begin{array}{c}30 \\
15 \\
10 \\
1.04\end{array}$ & $\begin{array}{c}35 \\
26 \\
20 \\
1.04\end{array}$ & $\begin{array}{c}33-40 \\
20-32 \\
18-20 \\
1.02-1.14\end{array}$ & $\begin{array}{l}{ }^{\circ} \mathrm{C} \\
{ }^{\circ} \mathrm{C} \\
{ }^{\circ} \mathrm{C}\end{array}$ \\
\hline loss processes & (9) & $\begin{array}{c}K_{R} \\
\vartheta_{G}\end{array}$ & $\begin{array}{c}0.015 \\
1.04\end{array}$ & $\begin{array}{l}0.05 \\
1.04\end{array}$ & $\begin{array}{c}0.001-0.171 \\
1.02-1.14\end{array}$ & day $^{-1}$ \\
\hline
\end{tabular}
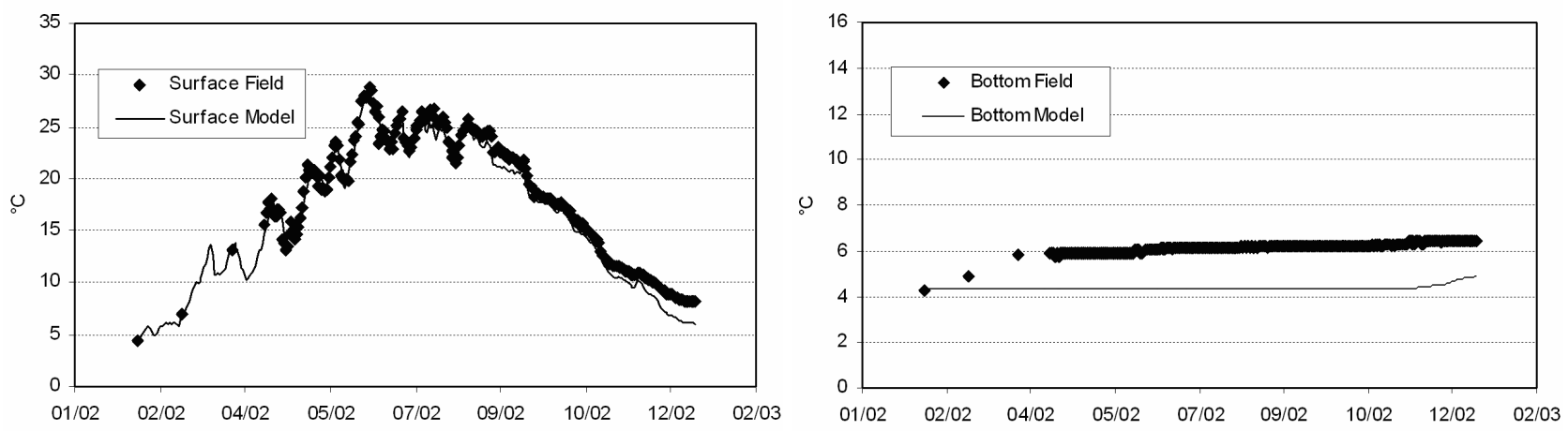

Fig. 2. Comparison between field and simulated temperature data.

Biomass losses due to sedimentation (S) were simulated by applying a simple constant settling velocity equal to zero for the buoyant species $P$. rubescens (Walsby 1994; Omlin et al. 2001) and equal to $0.1 \mathrm{~m}$ day $^{-1}$ for the $\mathrm{G} 2$ group.

The $\mathrm{PO}_{4}$ water sediment flux was simulated as a function of temperature and dissolved oxygen concentration at the water-sediment interface. Table 1 reports the principal model parameters for the Lake Pusiano application of CAEDYM.

In order to validate the model results a one year experimental campaign was carried out in 2002 during which time all input variables, required by DYRESM and CAEDYM were measured. Daily averaged meteorological data were supplied by the meteorological station of the Lombardy Regional Agency for Environmental Protection located in the city of Lecco (around $10 \mathrm{~km}$ far form the lake shore), and the discharge of the principal inflows was obtained from applying the hydrological model SWAT, previously calibrated, to the catchment (Salerno 2005).

The limnological campaign consisted of taking profile data at the deepest point of the lake. Hydrochemical parameters (nutrients, organic carbon, $\mathrm{pH}$, oxygen, con- ductivity) were measured in the water column at fortnightly intervals during maximum summer stratification and at monthly intervals during the rest of the year. Phytoplankton and zooplankton populations were concurrently sampled. The same sampling schedule was also applied to the principal tributaries. For details on the analytical methods see Legnani et al. (2005). Water temperature data were measured in continuous (every 15 minutes) by a thermistor chain at the point of maximum depth as well as on the principal tributary (every 30 minutes).

\section{RESULTS}

Figure 2 reports the first results of the hydrodynamics model for 2002. Surface temperatures varied from $4.5{ }^{\circ} \mathrm{C}$ at the beginning of February (maximum winter overturn) to 28.9 at the end of June (during maximum stratification). The comparison between field and simulated data related to the lake surface layer shows an excellent model performance $(\mathrm{R}=1, \mathrm{~N}=257)$ during the most of the year indicating a good simulation of the surface heat budged. On the bottom the seasonal temperature cycle is more smoothed with temperature ranging from 4.3 (at winter overturn) to $6.3^{\circ} \mathrm{C}$ (after the 

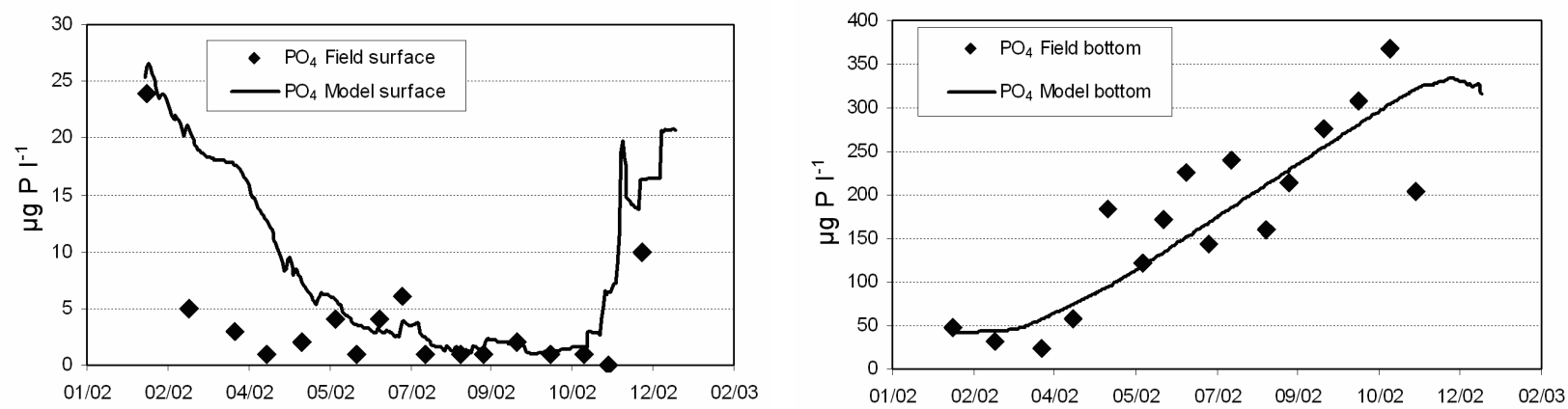

Fig. 3. Comparison between field and simulated $\mathrm{PO}_{4}$ data.
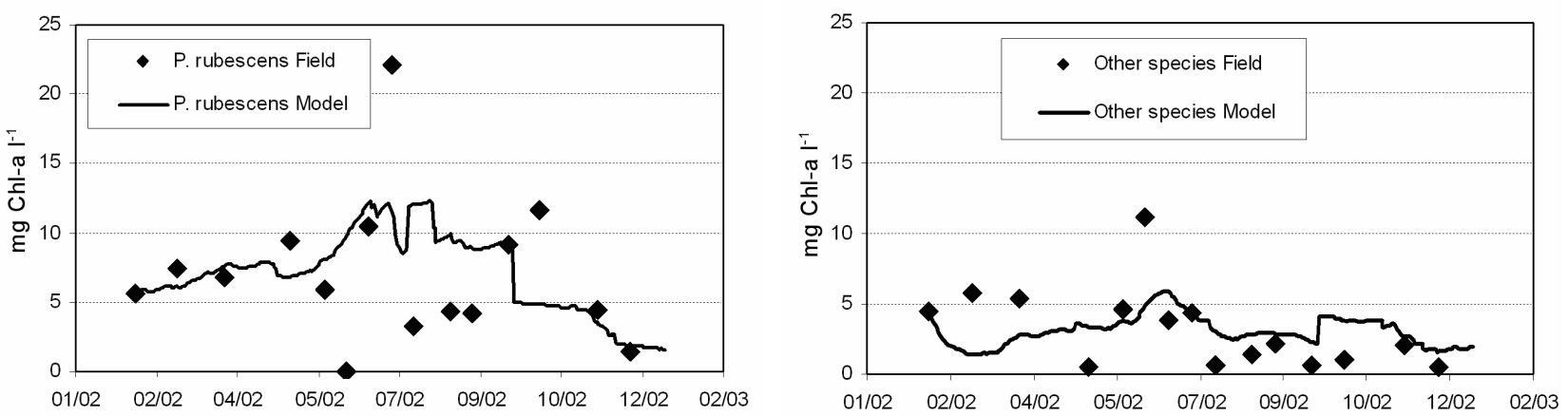

Fig. 4. Comparison between field and simulated data related to P. rubescens and G2 group (7.5 m depth).

onset of thermal stratification). The principal lack in model performances seems to be the inability in simulating the slight temperature increase during spring (weak stratification). This mismatch between field and simulated data is likely due to the use of daily averaged meteorological data instead of sub-daily data (not available for the whole simulated period) which smoothed the effects of the meteorological driving forces. In particular the simulation of mixing events driven by the wind action is highly sensitive to the temporal resolution of the input data (Imberger 1994). A possible explanation of the model failure is so a raw description of the turbulent kinetic energy budget along the water column during the period of weak stratification. After the onset of a stable thermal stratification, and the heat exchange reduction between upper and lower layers, a difference of around $2{ }^{\circ} \mathrm{C}$ persist for the rest of the year.

The comparison between field and simulated $\mathrm{PO}_{4}$ concentrations data are shown in figure 3 where it is seen that the model reproduced the seasonal trends of both the surface and bottom layers rather well. The model clearly accounted for the surface nutrient depletion, principally due to the phytoplankton uptake, and the bottom nutrient enrichment due to remineralization and release from sediments. In the surface layer $(\mathrm{R}=$ $0.7, \mathrm{~N}=17$ ) a better agreement was reached in the sec- ond half of the year when the difference in concentrations were constantly below $6 \mu \mathrm{g} \mathrm{P}^{-1}$.

On the bottom $(\mathrm{R}=0.9, \mathrm{~N}=16)$ the field data showed some variability that was absent in the simulated concentrations. Two reasons can be put forward to account for the different behavior of measured and simulated data. First, the sharp nutrient gradient that characterize the lower layers of the lake (around $30 \mu \mathrm{gP}$ $\mathrm{l}^{-1}$ between 15 and $22.5 \mathrm{~m}$ depth) amplifies differences in concentration due to errors in the sampling depth and second the dynamics of the benthic boundary layer which were turned off in this study.

In terms of phytoplankton dynamics (Fig. 4) the model reproduced the strong dominance of $P$. rubescens that represent about $70 \%$ of the total Chl- $a$ content. Passing from the chemical to the biological level it has also to be noted a general reduction of the agreement between measured and simulated data, as underlined by the decline of the regression coefficient which moves from $0.7-0.9$ for the $\mathrm{PO}_{4}$ concentrations to 0.3 and 0.4 for $P$. rubescens and G2 respectively. This is likely the effects of error dispersion arising from lower (e.g. hydrodynamics) to higher simulated levels (e.g. chemical and biological). Finally the model seems to smooth the peak of the phytoplankton dynamics giving an average response of the phytoplankton behavior. 


\section{DISCUSSION AND FUTURE GOALS}

On the basis of the authors' knowledge the PILE project represents the first attempt in simulating the hydrological and trophic behavior of the lake-catchment integrated system as a whole, in an Italian lacustrine environment. Despite the complexity of the system the first results of the in-lake modelling, seems to be encouraging as the model appears to be able to catch some key limnological phenomena related to both hydrodynamics and ecological processes at the seasonal scale. Model failures are likely due the low quality and/or low resolution of the input data for hydrodynamics (Imberger 1994) and to the difficulties in calibrating a number of parameters for the ecological simulations. From this point of view the simulation of only two algal groups represents an evident simplification of the ecosystem complexity as the G2 group is composed of species with different functional and morphological properties. A future goal of the project will be to extend the model simulation to a wider spectrum of algal groups in order to reach a better description of the ecosystem diversification. In general terms to be more effective the application of complex models needs an effort to improve the quality of the driving forces (meteorology and hydrology) and a more efficient relationship between modeler and experimental limnologists in order to reduce the uncertainty of the model parameters.

The future aims of the project will be to gain a better connection between the catchment and the in-lake modelling and to develop a three dimensional model of the lacustrine ecosystem, which seems to be of fundamental importance for the understanding of the lake responses at a sub-daily time scale.

\section{ACKNOWLEDGMENTS}

We wish to thank the Department of Lecco of the Lombardy Regional Agency for Environmental Protection for supplying the meteorological dataset. A special thank is due to Franco Salerno (Water Research Institute - National Research Council) for his fundamental work on the modelling of the Lake Pusiano catchment.

Received: August 2005

Accepted: December 2005

\section{REFERENCES}

Antenucci, J. \& A. Imerito. 2002. The CWR DYnamic Reservoir Simulation Model: DYRESM_Science Manual. Centre for Water Research, University of Western Australia, Nedlands, WA 6907, AUSTRALIA: 49 pp.

Copetti, D. 2005. Modelling the effects of nutrients loads and hydrodynamic regime on the phytoplankton and zooplankton populations in lacustrine environment. Doctoral thesis, University of Milan: $109 \mathrm{pp}$.

Hamilton, D. P. \& S. G. Schladow. 1997. Prediction of water quality in lakes and reservoirs. Part I - Model description. Ecol. Model., 96: 91 - 110.

Imberger, J. 1994. Transport processes in lakes: A review article, In: Margalef, R. (Ed.), Limnology Now: A Paradigm of Planetary Problems. Elsevier Science B.V.: 99-193.

Jellison, S. W. \& J. M. Melack. 1993. Meromixis and vertical diffusivities in hypersaline Mono Lake. Limnol. Oceanogr., 38: 1008-1009.

Kurmayer, R. \& F. Jüttner. 1999. Strategies for the co-existence of zooplankton with the toxic cyanobacterium Planktothrix rubescens in Lake Zürich. J. Plankton Res., 21: 659-683.

Legnani, E., D. Copetti, A. Morabito, G. Tartari, M.T. Palumbo \& G. Morabito. 2005. Planktothrix rubescens' seasonal and vertical distribution in Lake Pusiano (North Italy). J. Limnol., 64(1): 61-73.

Omlin, M., P. Reichert \& R. Foster. 2001. Biogeochemical model of Lake Zürich: model equations and results. Ecol. Model., 141: 77-103.

Romero, J.R., M.R. Hipsey, J.P. Antenucci \& D. Hamilton. 2003. Computational Aquatic Ecosystem Model: CAEDYM v2. Science Manual. Centre for Water Research, University of Western Australia, Nedlands, WA 6907, AUSTRALIA: $85 \mathrm{pp}$.

Salerno, F. 2005. Utilizzo di sistemi radar meteorologici nella modellizzazione degli apporti di nutrienti ai corpi idrici superficiali. Tesi di dottorato, Università dell'Insubria di Como: 333 pp.

Walsby, A.E. 2001. Determining the photosynthetic productivity of a stratified phytoplankton population. Aquat. Sci., 63: $18-43$.

Walsby, A.E. 1994. Gas vesicles. Microbiol. Rev., 58: 94-144.

Wallace, B., D. Hamilton \& J. Patterson. 1996. Response of photosynthesis models to light limitation. Int. Revue ges. Hydrobiol., 81: 315-324.

Webb, W.L., W. Newton \& D. Starr. 1974. Carbon dioxide exchange of Alnus rubra a mathematical model. Oecologia. 17: 281-291. 